\title{
Tratamientos antimicrobianos abreviados en pacientes adultos
}

\author{
ALBERTO FICA C.
}

Short-term antimicrobial therapy in adult patients

Short-term antibiotic therapy is an alternative for managing community-acquired infections that may improve compliance, decrease acquisition costs and limit potential drug-related adverse effects. Several trials have validated its use in streptococcal pharyngitis, acute bacterial sinusitis, noncomplicated acute cystitis, urethritis, and certain types of community-acquired pneumonia or diarrheal syndrome with similar efficacy and safety than a standard or reference treatment. Short-term antibiotic therapy represents currently the standard modality of treatment for certain types of infectious diarrhea, non-complicated acute cystitis or urethritis of different etiologies. In communityacquired pneumonia, only azithromycin has been validated and is restricted for outpatient settings. This compound is probably the most efficient choice for patients with pneumonia and associated comorbidity that do not require admission if pneumococcal resistance to macrolides remains low. Moreover, azithromycin together with dirithromycin and telithromycin represent good alternatives for acute exacerbations of chronic bronchitis. Higher acquisition costs restrain the potential advantages of shortterm therapy for streptococcal tonsillitis and acute bacterial sinusitis.

Key words: Short-term antibiotic therapy, Community acquired infections.

Palabras claves: Terapia antimicrobiana abreviada; Infecciones adquiridas en la comunidad.

\section{Introducción}

Tradicionalmente los antimicrobianos han sido aplicados por períodos de 7 o más días para el tratamiento de numerosas condiciones mórbidas en la comunidad. Estos períodos han sido derivados de observaciones empíricas más que controladas y estuvieron ligados a los resultados dramáticos observados a mediados del siglo XX para el tratamiento de la neumonía neumocóccica o la fiebre tifoidea.

El advenimiento de compuestos bactericidas con una buena biodisponibilidad oral y un perfil farmacocinético optimizado, ha permitido acortar estas terapias y desarrollar trabajos randomizados que han validado este tipo de tratamiento. Definiremos arbitrariamente en esta publicación como terapia abreviada o acortada, la utilización de prescripciones de antimicrobianos por un plazo igual o menor a 5 días para patologías comunes de la comunidad.

Esta modalidad permite mejorar la adherencia, potencialmente disminuir los costos del tratamiento y los efectos adversos de los medicamentos, sin perjudicar la eficacia clínica del mismo. Las condiciones potenciales de ser tratadas bajo este concepto se presentan en la Tabla 1.

\section{Faringitis estreptocóccica}

El objetivo fundamental del tratamiento antimicrobiano de esta condición es prevenir el desarrollo de la fiebre reumática ${ }^{1-5}$. Las intervenciones con antimicrobianos tienen nulo o mínimo impacto para acortar el período de estado de la enfermedad $^{6-8}$. El tratamiento de referencia es fenoximetilpenicilina (penicilina V) $250 \mathrm{mg}$ c/6h durante 10 días o amoxicilina oral $500 \mathrm{mg}$ c/8h. En la Tabla 2 se señalan formas abreviadas de

Sección de Infectología, Departamento de Medicina, Hospital Clínico Universidad de Chile.

Recibido: 26 junio 2003

Aceptado: 23 marzo 2004 
Tabla 1. Tratamiento abreviado con antimicrobianos para patologías de la comunidad en pacientes adultos

Faringitis estreptocóccica

Sinusitis bacteriana aguda

Neumonía adquirida en la comunidad (ciertos tipos)

Bronquitis crónica reagudizada

Cistitis aguda no complicada

Síndrome diarreico agudo

Uretritis aguda

tratamiento que han sido validadas en diferentes ensayos con sus costos relativos ${ }^{2,9-11}$. En estos ensayos se ha utilizado como marcador de eficacia clínica, la erradicación de Streptococcus pyogenes de la faringe, ya que este fenómeno se asocia a la disminución del riesgo de desarrollar fiebre reumática. Los porcentajes de erradicación superan en general el $90 \%$.

En la Tabla 2 se puede observar que la aplicación intramuscular de penicilina benzatínica (que tiene una adherencia obligada y un bajo costo de adquisición), posee un costo de administración elevado y además presenta el inconveniente del dolor local. De las otras alternativas abreviadas, sólo amoxicilina en dosis de $1 \mathrm{~g} \mathrm{c} / 12$ oral durante 6 días representa un esquema de igual costo que las prescripciones tradicionales ${ }^{9}$. En este contexto, las nuevas alternativas disponibles como macrólidos, cetólidos o cefalosporinas de tercera generación, no representan un ahorro en el tratamiento aunque podrían mejorar la adherencia ${ }^{2,10-11}$. $\mathrm{La}$ evidencia publicada tampoco señala una mejor tolerancia para estos compuestos ${ }^{2}$. Una polémica existe relativa a la duración mínima que debería tener el tratamiento con azitromicina oral debido a una mayor frecuencia de recaída en pacientes pediátricos con esquemas de 3 días $^{12}$. Ello a pesar de una favorable respuesta inicial para obtener la erradicación de S. pyogenes ${ }^{10,13}$. Hasta que este punto quede dilucidado es conveniente utilizar un tratamiento con este compuesto durante 5 días. Se debe recordar al lector, que antes de iniciar un tratamiento para una faringitis estreptocóccica, debe confirmar microbiológicamente el diagnóstico debido a la baja prevalencia de este agente (que no supera el 20\%), aun cuando se tenga una alta sospecha clínica ${ }^{1,2}$. La utilización de $\beta$-lactámicos en atención primaria ha contribuido en la selección de cepas de Streptococcus pneumoniae resistentes a penicili$\mathrm{na}^{14,15}$.

\section{Sinusitis bacteriana aguda}

La utilización de antimicrobianos permite acortar el período de morbilidad en la sinusitis bacteriana aguda en comparación al uso de placebo y disminuir la intensidad de los síntomas. Los pacientes que no reciben antimicrobianos evolucionan a la mejoría espontánea en aproximadamente $70 \%$ de los casos, cifra que se incrementa a $86-92 \%$ cuando estos compuestos son indica$\operatorname{dos}^{16}$. El tratamiento de referencia de una sinusitis bacteriana aguda es amoxicilina oral durante 10 días $^{17,18}$. La mayor parte de los ensayos clínicos han sido realizados efectuando comparaciones con amoxicilina y no contra placebo y su

Tabla 2. Tratamientos de referencias y esquemas alternativos abreviados para el tratamiento de la faringitis estreptocóccica

\begin{tabular}{|c|c|c|c|}
\hline Antimicrobiano & Dosis & $\begin{array}{l}\text { Duración } \\
\quad \text { (ds) }\end{array}$ & $\begin{array}{c}\text { Costo relativo* } \\
\text { Precios netos sin impuestos }\end{array}$ \\
\hline \multicolumn{4}{|c|}{ Esquemas recomendados } \\
\hline PNC oral & $250 \mathrm{mg} \mathrm{c} / 6 \mathrm{~h}$ & 10 & 1 \\
\hline Amoxicilina & $500 \mathrm{mg} \mathrm{c} / 8 \mathrm{~h}$ & 10 & 1 a 5,5 \\
\hline \multicolumn{4}{|c|}{ Esquemas abreviados } \\
\hline PNC benzatina & 1.200.000 U im & 1 & $0,4$ (aplicado 1,1 a 1,9$)^{* *}$ \\
\hline Amoxicilina & 1 gramo c/12 h & 6 & 1 a 2,5 \\
\hline Cefixima & $400 \mathrm{mg} /$ día & 5 & 10,7 \\
\hline Azitromicina & $500 \mathrm{mg} /$ día & 5 & 12,7 a 19,7 \\
\hline Telitromicina & $800 \mathrm{mg} /$ día & 5 & 12,4 \\
\hline
\end{tabular}

*: En comparación con un esquema oral de PNC V por 10 días según costo de adquisición publicado en revista Kayros $\mathrm{N}^{\circ} 165$ de octubre del 2003 (1.356 pesos para 3 cajas de comprimidos de 1 millón de U a una dosis de medio comprimido oral cada 6 horas equivalente a $300 \mathrm{mg}$ por dosis). Los rangos señalan los costos para el mismo compuesto ofrecido por diferentes laboratorios. El costo de adquisición fue calculado de acuerdo al número mínimo de cajas necesarias para cubrir el período de tratamiento. Cuando fue posible, se incluyó el costo de un preparado bioequivalente; **: la administración debe considerar además el costo de una ampolla de agua destilada, de una jeringa de 5 ml y la aplicación intramuscular. 
objetivo ha sido demostrar la misma eficacia que la medicación de referencia. Un meta-análisis reciente logró identificar 10 estudios comparativos aceptables con azitromicina y que involucraron a 1.742 pacientes $^{10}$. Nueve de estos ensayos fueron realizados con esquemas abreviados $(1.500$ $\mathrm{mg}$ en 3 días) y los resultados fueron equivalentes a los comparadores (amoxicilina, amoxicilina/ ácido clavulánico, roxitromicina, cefaclor y otros por 10 a 14 días). Estudios posteriores con telitromicina han señalado una eficacia equivalente a fármacos tradicionales ${ }^{11}$.

Azitromicina es una medicamento de efecto bactericida sobre los principales agentes patógenos de infecciones respiratorias altas y bajas en la comunidad, asociado a un efecto post-antibiótico prolongado. Este compuesto se concentra, gracias a sus propiedades lipofílicas, en monocitos, leucocitos polimorfonucleares (PMN) y en macrófagos alveolares hasta concentraciones muy superiores a las observadas en el plasma o tejidos vecinos y que permiten sobrepasar varias veces las CIMs de las patógenos bacterianos habituales en infecciones respiratorias $^{13,19}$. La relación entre la concentración en PMN y el medio exterior es cercana a 80 , la relación entre macrófagos alveolares y el plasma es superior a 800 , sobre 158 en la mucosa bronquial y de 67 para muestras de expectoración. Una propiedad adicional de azitromicina es su larga vida media (> 30 a 40 horas) que facilita esquemas abreviados con concentraciones intracelulares útiles detectables por más de una semana $^{13,19}$.

Azitromicina y telitromicina pueden ser consideradas para un tratamiento abreviado, potencialmente de mejor adherencia aunque asociadas a un mayor costo de adquisición y probablemente no constituyan opciones costo-efectivas (Tabla 3). Para algunos expertos, un tratamiento acortado con azitromicina o telitromicina no es aún una alternativa aceptable y ellas no pueden ser consideradas en el manejo de pacientes con sinusitis complicada, reagudizaciones de un cuadro crónico o cuadros asociados a un origen dental.

En el tratamiento de la sinusitis bacteriana aguda, lo fundamental es identificar adecuadamente los casos de infección bacteriana y no sobretratar las infecciones virales con antimicrobianos. Diferentes recomendaciones y consensos promueven la utilización de un sistema de puntaje clínico para reconocer estos cuadros. Los mejores predictores clínicos corresponden a un número reducido de síntomas y signos, los que en forma combinada aumentan la probabilidad de enfermedad de causa bacteriana y que incluyen: odontalgia maxilar, escasa respuesta al uso de descongestionantes, rinorrea purulenta y una transiluminación anormal. Debido a que la mayor parte de los casos de sinusitis bacteriana se presentan con posterioridad a un cuadro gripal, se ha utilizado la propia persistencia de los síntomas respiratorios por más de una semana como una forma de discriminar a aquellos pacientes afectados por esta complicación de aquellos que tenderán a la mejoría espontánea. Sin embargo, la sola persistencia de ellos es de baja especificidad ya que una fracción importante de los pacientes con infecciones virales puede prolongar su sintomatología más allá de este período. La radiografía convencional no ofrece mayor sensibilidad que este sistema y la TAC adolece de una baja especificidad, además de su mayor costo. El lector interesado puede consultar algunas revisiones sobre este tema ${ }^{16-18}$.

\section{Neumonía adquirida en la comunidad}

Actualmente, sólo azitromicina ha sido validada en el tratamiento acortado de las neumonías adquiridas en la comunidad. Las evidencias de su eficacia en esta patología provienen de diferentes ensayos randomizados y de al menos un metaanálisis ${ }^{20}$.

Tabla 3. Alternativas abreviadas para el tratamiento de la sinusitis bacteriana aguda

\begin{tabular}{|c|c|c|c|}
\hline Compuesto & Dosis & $\begin{array}{l}\text { Duración } \\
\quad \text { (ds) }\end{array}$ & $\begin{array}{c}\text { Costo relativo } \\
\text { Precios netos sin impuestos }\end{array}$ \\
\hline $\begin{array}{l}\text { De elección } \\
\text { - Amoxicilina }\end{array}$ & $500 \mathrm{mg} \mathrm{c} / 8 \mathrm{~h}$ oral & 10 & $1 *$ \\
\hline $\begin{array}{l}\text { Terapias abreviadas } \\
\text { - Azitromicina } \\
\text { - Azitromicina } \\
\text { - Telitromicina }\end{array}$ & $\begin{array}{l}500 \mathrm{mg} \text { oral } \\
500 \mathrm{mg} \\
\text { luego } 250 \mathrm{mg} \\
800 \mathrm{mg} / \mathrm{d}\end{array}$ & $\begin{array}{l}3 \\
1 \\
4 \\
5\end{array}$ & $\begin{array}{c}4,1-8,1 \\
4,1-8,1 * * \\
10,2\end{array}$ \\
\hline
\end{tabular}

*: Los costos hacia octubre del 2003 (Revista Kayros $\mathrm{N}^{\circ} 165$ ), alcanzaban a $\sim 1.650$ pesos para un tratamiento con amoxicilina por 10 días; **: asume fragmentar los comprimidos de $500 \mathrm{mg}$ de una caja de 3 unidades. 
En este meta-análisis, los autores lograron identificar 15 trabajos randomizados donde azitromicina fue comparada contra eritromicina, claritromicina, roxitromicina, cefaclor, amoxicilina/ácido clavulánico o PNC G en dosis estándares para el tratamiento de neumonías típicas, atípicas o mixtas. El meta-análisis incluyó al menos dos estudios en neumonías atípicas y otros cinco en neumonías de etiología mixta ${ }^{20}$. Los estudios con azitromicina incluyeron esquemas por 3 ó 5 días, aunque en todos los casos (salvo un estudio con $3.000 \mathrm{mg}$ ) la dosis aplicada fue de $1.500 \mathrm{mg}$ totales. La tasa global de fracaso con los comparadores fue de $9,8 \%$ y con azitromicina $6,0 \%$, siendo incluso esta diferencia significativa a favor de azitromicina. (odds ratio 0,63; IC95 0,42 a 0,95 ) Los mencionados ensayos no incluyeron estudios con quinolonas de tercera o cuarta generación o pacientes hospitalizados y excluyeron en general pacientes inmunocomprometidos. Ensayos individuales señalan la utilidad y alta tasa de curación de azitromicina en un esquema de 3 días para el manejo de pacientes con infección por Mycoplasma pneumoniae ${ }^{21}$.

La eficacia terapéutica de azitromicina y su perfil de tolerancia similar a las otras alternativas para el manejo de las neumonías comunitarias de manejo ambulatorio, ha permitido su inclusión o recomendación, junto a otros macrólidos en diferentes guías terapéuticas sobre neumonía comunitaria. Estos compuestos aparecen como alternativa antimicrobiana de primera línea en las recomendaciones de la Infectious Diseases Society of America - IDSA, y las pautas elaboradas en conjunto entre la Canadian Infectious Diseases Society y la Canadian Thoracic Society hacia el año 2000 para el tratamiento de pacientes ambulatorios sin comorbilidad ${ }^{22,23}$. Los macrólidos, también son mencionados como una alternativa en las guías elaboradas por el Consenso sobre neumonía comunitaria elaborado por la Sociedad Chilena de Enfermedades Respiratorias $^{24}$. La aplicación de azitromicina en el manejo de las neumonías comunitarias no graves es aceptada pero permanece en polémica la duración que debería tener este tratamiento. Algunos expertos consideran que un tratamiento acortado con azitromicina no puede ser recomendado, especialmente ante infecciones por Chlamydia pneumoniae debido a la tendencia que presenta este patógeno a recurrir a pesar de un curso apropiado de antimicrobianos ${ }^{25,26}$. Los esquemas acortados no han sido validados para cuadros de legionelosis.

Para pacientes ambulatorios sin comorbilidad (grupo I de la American Thoracic Society- ATS), diferentes sociedades científicas recomiendan hasta la fecha a amoxicilina o eritromicina oral durante 10 días como tratamientos preferenciales (ATS excluyó a los macrólidos como monoterapia de pacientes en el grupo I en las pautas elaboradas el año 2001). Los macrólidos no pueden ser considerados como alternativa terapéutica en pacientes con neumonías aspirativas o estafilocóccicas.

Los mayores costos de adquisición de azitromicina no la convierten en una alternativa eficiente para los pacientes denominados ATS I, ya que el costo relativo de adquisición es superior en al menos 5 veces a los valores de un tratamiento con eritromicina o amoxicilina para este tipo de pacientes, aunque pudiera mejorar la adherencia al tratamiento. No obstante esta desventaja, azitromicina es tal vez la alternativa más eficiente para el tratamiento de los pacientes del grupo ATS II (pacientes de manejo ambulatorios con comorbilidad) (Tabla 4). Para estos casos, el costo de una terapia abreviada con azitromicina representa entre 12 y $50 \%$ del valor de un tratamiento con amoxicilina con inhibidores de $\beta$ lactamasas, cefalosporinas de segunda generación, otros macrólidos activos contra Haemophilus influenzae o quinolonas "respiratorias".

Los límites de una terapia abreviada con azitromicina para pacientes con neumonía comunitaria, están dictados por la frecuencia de $S$. pneumoniae resistentes a macrólidos en una población determinada, ello porque su existencia se ha asociado a fracasos terapéuticos graves en pacientes con neumonías neumocóccicas bacteriémicas. Esta cifra no supera actualmente el $10 \%$ en Chile ${ }^{27}$.

\section{Bronquitis crónica reagudizada}

Los episodios de reagudización de bronquitis crónica son gatilladas la mayor parte de las veces por infecciones bacterianas. Otras causas de descompensación incluyen infecciones respiratorias virales, cambios climáticos estacionales, medicamentos y exposición a irritantes ambientales o intradomiciliarios ${ }^{28,29}$. Los tres agentes bacterianos más importantes involucrados corresponden a $S$. pneumoniae, $H$. influenzae y Moraxella catarrhalis $^{28,29}$. La participación de agentes virales, $C$. pneumoniae o M. pneumoniae en estas descompensaciones es menos clara. El papel gravitante del cuadro inflamatorio explica la respuesta limitada al uso de antimicrobianos y las dificultades encontradas para demostrar un beneficio con ellos. El manejo ambulatorio de estos pacientes contempla variados aspectos e incluye el cese del tabaquismo, la disminución de exposi- 
Tabla 4. Esquemas terapéuticos y costos de adquisición para el manejo de neumonía de la comunidad en pacientes con condiciones comórbidas y sin criterios de hospitalización

\begin{tabular}{|c|c|c|c|}
\hline Antimicrobiano & Dosis & $\begin{array}{l}\text { Duración } \\
\quad \text { (ds) }\end{array}$ & $\begin{array}{l}\text { Costo aproximado } \\
\text { año } 2003 \text { en pesos* }\end{array}$ \\
\hline $\begin{array}{l}\text { Amoxicilina/ác.clavulánico } \\
\text { (tres dosis diarias) }\end{array}$ & $500 / 125 \mathrm{mg} \mathrm{c} / 8 \mathrm{~h}$ & 10 & 29.925 \\
\hline $\begin{array}{l}\text { Amoxilina/ác.clavulánico } \\
\text { ( } 2 \text { dosis diarias) }\end{array}$ & $875 / 125 \mathrm{mg} \mathrm{c} / 12 \mathrm{~h}$ & 10 & $9.073-26.670$ \\
\hline Cefuroxima axetil & $500 \mathrm{mg} \mathrm{c} / 12 \mathrm{~h}$ & 7 a 14 & $30.694-61.388$ \\
\hline Cefprozilo & $500 \mathrm{mg} \mathrm{c} / 12 \mathrm{~h}$ & 7 a 10 & 30.096 \\
\hline \multirow[t]{2}{*}{ Claritromicina } & $250 \mathrm{mg} \mathrm{c} / 12 \mathrm{~h}$ & 10 & $14.460-34.216$ \\
\hline & $500 \mathrm{mg} \mathrm{c} / 12 \mathrm{~h}$ & 10 & $19.394-66.964$ \\
\hline \multirow[t]{3}{*}{ Azitromicina** } & $500 \mathrm{mg}$ c/día & 3 & $6.796-13.369$ \\
\hline & 500 mg/día & 1 & $8.614-13.369$ \\
\hline & y luego $250 \mathrm{mg}$ c/día & 4 & \\
\hline Levofloxacina & $500 \mathrm{mg}$ c/día & 7 a 14 & 16.590 a 33.180 \\
\hline Moxifloxacina & 400 mg c/día & 10 & 22.273 \\
\hline
\end{tabular}

*: tomados de Revista Kayros $\mathrm{N}^{\circ} 165$, octubre del 2003 (paridad cambiaria US $\$=700$ pesos); **: Probablemente no útil ante infecciones por C. pneumoniae y no validado para Legionellosis; $* * *$ No hay presentaciones originales o bioequivalentes de $250 \mathrm{mg}$.

ción a irritantes, inmunizaciones, medidas farmacológicas (broncodilatadores), oxígeno domiciliario y antimicrobianos ${ }^{28}$. Los cuadros de bronquitis crónica reagudizada se reconocen por un aumento de la disnea, aumento del volumen de expectoración o el cambio hacia una expectoración purulenta. El beneficio del tratamiento antimicrobiano es más evidente cuando dos o tres de estas características están presentes ${ }^{29}$.

Dos de los principales agentes infecciosos asociados a las exacerbaciones de esta condición, $H$. influenzae y $M$. catarrhalis, son resistentes en frecuencia variable a ampicilina o amoxicilina por un mecanismo enzimático. Sobre 90\% de los aislados de M. catarrhalis y $30 \%$ de los aislados de $H$. influenzae poseen $\beta$-lactamasas que limitan la utilidad de estos compuestos en el tratamiento de las reagudizaciones. Por otra parte, la selección de cotrimoxazol o tetraciclinas no es viable por la frecuencia creciente de resistencia a estos compuestos observada en aislados de S. pneumoniae.

Los compuestos actualmente recomendados para el tratamiento de estas regudizaciones incluyen a amoxicilina/ácido clavulánico, nuevos macrólidos como claritromicina, azitromicina o diritromicina, quinolonas "respiratorias" o cetólidos como telitromicina ${ }^{29-32}$. Las recomendaciones sobre la duración del tratamiento varían de 7 a 14 días, reservando los períodos más prolongados a los pacientes más comprometidos. Sólo algunos compuestos han sido validados en terapias abreviadas e incluyen ciertos macrólidos, cetólidos y amoxicilina/ácido clavulánico $^{20,30-32}$ (Tabla 5). Las ventajas farma- cocinéticas potenciales de un tratamiento abreviado con azitromicina, así como las limitaciones derivadas de la resistencia a macrólidos en aislados de $S$. pneumoniae, son aplicables en esta condición al igual que en los casos de neumonía comunitaria.

\section{Cistitis aguda no complicada}

Los tratamientos abreviados se han convertido en la alternativa terapéutica más racional para el tratamiento de cistitis aguda no complicada. Por definición, este grupo de infecciones urinarias incluye sólo aquellas infecciones bajas, en ausencia de alteraciones anatómicas y funcionales de la vía urinaria.

Tabla 5. Antimicrobianos potencialmente útiles en esquemas abreviados para el manejo empírico de episodios de bronquitis crónica reagudizada (esquemas de 5 días)

Azitromicina en esquema de 3 ó 5 días $(1.500 \mathrm{mg}$ totales)

Diritromicina (500 mg al día oral)

Telitromicina (800 mg al día oral)

Amoxicilina/ác clavulánico (875/125 mg cada 12 horas oral)

No sugeridos por resistencia

Amoxicilina

Cotrimoxazol

Tetraciclina 
Tabla 6. Esquema comparativo para diferentes esquemas de terapia para cistitis aguda no complicada según su duración

\begin{tabular}{lccc}
\hline & Dosis única & 3 días & 7 días \\
\hline Tasa de erradicación & + & +++ & +++ \\
Tasa de recurrencia & +++ & ++ & + \\
Efectos adversos & + & ++ & +++ \\
Adherencia & +++ & ++ & + \\
Costo & + & ++ & +++ \\
\hline
\end{tabular}

La evidencia recogida a través de diferentes ensayos controlados y al menos un meta-análisis, indica que los tratamientos con una sola dosis, son inferiores en eficacia en comparación a tratamientos más prolongados. De la misma manera, para algunos compuestos específicos, la eficacia de un tratamiento durante 3 días es similar a un tratamiento estándar durante 7 días, sin aumentar significativamente la tasa de recurrencias y con una tendencia a una menor tasa de efectos adver$\operatorname{sos}^{33}$. En la Tabla 6 se resumen las ventajas y desventajas cualitativas de diferentes formas de tratamiento abreviado.

Los esquemas por 3 días han ganado amplia aceptación porque representan el mejor equilibrio entre las variables presentadas en la Tabla 6 . Debido a las altas tasas de resistencia ante cotrimoxazol o ampicilina en aislados de Escherichia coli asociados a infecciones urinarias, los esquemas empíricos iniciales no pueden incluir estos compuestos en nuestro medio.

Independientemente a la utilización de formas abreviadas de terapia y a su uso empírico inicial, todos los eventos de infección urinaria deben ser confirmados microbiológicamente con una toma de muestra anterior a la primera dosis del antimicrobiano.

La baja tasa actual de resistencia a quinolonas en aislados de infecciones urinarias comunitarias, permite plantear su uso en estos esquemas (Tabla 7). La experiencia en tratamientos acortados con compuestos $\beta$-lactamicos o nitrofurantoína es insuficiente o se ha asociado a un mayor porcentaje de fracaso terapéutico o recurrencia, en comparación con otros esquemas abreviados y su uso no se recomienda.

Los tratamientos abreviados en infecciones urinarias no son aplicables en pacientes embarazadas o con pielonefritis aguda, en pacientes de sexo masculino o en cualquier paciente con alteraciones anatómicas o funcionales de las vías urinarias.
Tabla 7. Esquemas empíricos iniciales para cistitis aguda no complicada (3 días)*

\begin{tabular}{ll}
\hline Ciprofloxacina & $250 \mathrm{mg} \mathrm{c} / 12 \mathrm{~h}$ oral \\
Norfloxacina & $400 \mathrm{mg} \mathrm{c} / 12 \mathrm{~h}$ oral \\
Levofloxacina & $500 \mathrm{mg}$ al día oral \\
\hline
\end{tabular}

*: debe ser respaldado por la obtención de un examen de orina y urocultivo previamente.

\section{Síndrome diarreico agudo}

La mayor parte de los casos de diarrea aguda en la comunidad son de evolución autolimitada y no requieren tratamiento específico. Los antimicrobianos además no son de utilidad cuando el estudio microbiológico identifica ciertos patógenos como salmonelas zoonóticas, Campylobacter jejuni o Isospora belli en pacientes inmunocompetentes ${ }^{34}$.

Las condiciones que pueden beneficiarse de un tratamiento antimicrobiano corresponden a diarreas por Vibrio parahaemolyticus, Shigella sp., Entamoeba histolytica o Giardia lamblia ${ }^{34}$. El tratamiento puede también ser indicado sobre bases empíricas, donde probablemente están involucrados estos agentes y siempre bajo un estudio microbiológico inicial.

La quinolonas y algunos nitrofuranos han sido utilizados exitosamente bajo terapias abreviadas para el tratamientos de ciertos pacientes adultos afectados con diarrea ${ }^{34-38}$ (Tabla 8).

\section{Uretritis aguda}

Las dificultades para lograr una adherencia apropiada han motivado la búsqueda de tratamientos abreviados para el manejo de pacientes con uretritis aguda. Actualmente en Chile, el tratamiento recomendado para pacientes con sospecha de uretritis aguda gonocóccica consiste en dosis única de $500 \mathrm{mg}$ de ciprofloxacina. Este esquema ha reemplazado a penicilina como alter- 
Tabla 8. Esquemas abreviados para pacientes adultos con diarrea

\section{Duración (días)}

Tratamiento empírico inicial en casos de diarrea persistente o disentería*

Ciprofloxacina

Fleroxacina

Norfloxacina

Nifuroxazide

Shigelosis

Norfloxacina

Ciprofloxacina

Azitromicina

Giardiasis

Tinidazol
$500 \mathrm{mg} \mathrm{c} / 12 \mathrm{~h}$ oral

$400 \mathrm{mg} /$ día oral

$400 \mathrm{mg}$ c/12 h oral $400 \mathrm{mg} /$ día oral

$400 \mathrm{mg} \mathrm{c} / 12 \mathrm{~h}$ oral

$800 \mathrm{mg}$ oral

1 gramo oral o $500 \mathrm{mg} \mathrm{c} / 12 \mathrm{~h}$ oral

$500 \mathrm{mg}$, luego $250 \mathrm{mg} /$ día

$2 \mathrm{~g}$
5

5

5

5

1

5

1 día - 4 días

1

*: con estudio microbiológico solicitado y pendiente

nativa de primera elección debido a la resistencia detectada a este compuesto en aislados de Neisseria gonorrhoeae en el concierto nacional. Otras alternativas propuestas para el manejo de uretritis gonocóccica se señalan en la Figura 1 y ellas contemplan a cefixima (cefalosporina de tercera generación), levofloxacina (quinolona de tercera generación), o ceftriaxona intramuscular (indicada como primera instancia en mujeres embarazadas) ${ }^{39}$. Todas ellas se administran en una sola dosis para asegurar la adherencia al tratamiento. Es necesario mencionar que la aplicación de

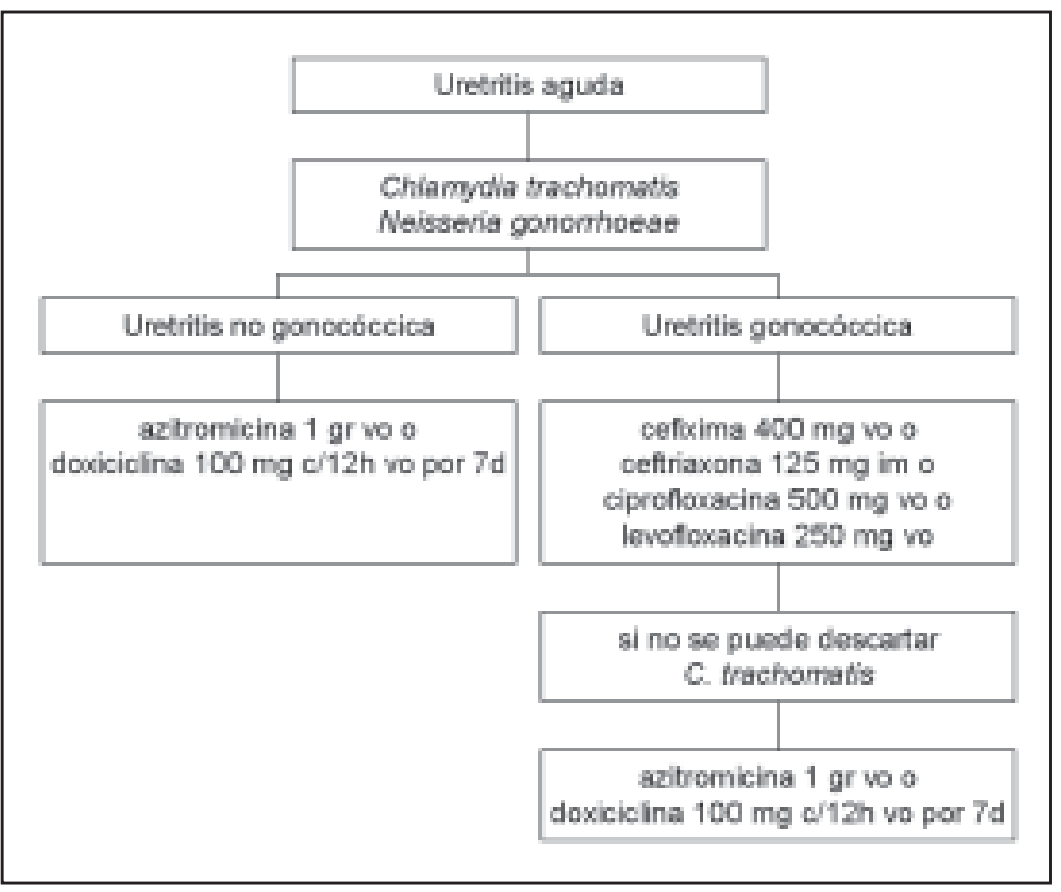

Figura 1. Diagrama terapéutico para la uretritis aguda según etiología. cefixima en estos casos resulta desproporcionada ya que involucra una alternativa oral de amplio espectro en una patología comunitaria donde otras alternativas son igualmente eficaces.

Hasta hace poco no se contaban con tratamientos abreviados para el tratamiento de la uretritis no gonocóccica (habitualmente causada por Chlamydia trachomatis); sin embargo, diversos estudios han permitido sustentar la prescripción de monodosis de azitromicina para esta condición $^{40}$. Las tasas de respuesta con $1 \mathrm{~g}$ en dosis única, son similares a un tratamiento con doxiciclina durante 7 días y se asocian a un buen perfil de tolerancia. Las terapias abreviadas son de gran importancia en el tratamiento de la uretritis aguda, ya que ellas permiten una adherencia y facilitan el tratamiento de los contactos sexuales.

Los casos de uretritis aguda deben contar idealmente con un estudio etiológico para dirigir adecuadamente la terapia. Cuando ello no es posible, estos pacientes son manejados en forma sindromática asumiendo que la coinfección por $N$. gonorrhoeae y $C$. trachomatis es frecuente y que ambas deben ser incluidas en la terapia prescrita. Para ello también es posible utilizar tratamientos abreviados. (p ej.: ciprofloxacina y azitromicina). 


\section{Resumen}

Los tratamientos abreviados con antimicrobianos son una alternativa atractiva en medicina ambulatoria, los que potencialmente pueden mejorar la adherencia, disminuir los efectos adversos y los costos de adquisición de una terapia. Diversos ensayos avalan su uso en el manejo de pacientes con faringitis estreptocóccica, sinusitis bacteriana aguda, neumonía adquirida en la comunidad, síndrome diarreico agudo, cistitis aguda no complicada y uretritis aguda, con eficacias y tolerancia similares a tratamientos de referencia. Para el manejo de pacientes con faringitis estreptocóccica o sinusitis bacteriana, esta forma terapéutica no se asocia a una disminución del costo de adquisición aunque podría mejorar la adherencia. En contraste, tratamientos abreviados de diferente extensión representan actualmente el estándar para el manejo de pacientes con diarrea por agentes específicos, cistitis aguda no complicada o uretritis de diferentes etiologías. En el caso de neumonías comunitarias, sólo azitromicina podría ser utilizada en terapias abreviadas, representando tal vez la alternativa más costo-efectiva para pacientes con morbilidad asociada que no requieren hospitalización. Este último compuesto junto a diritromicina y telitromicina aparecen como alternativas en el tratamiento abreviado de pacientes con bronquitis crónica reagudizada.

\section{Bibliografía}

1.- Bisno A L, Gerber M A, Gwaltney J M, Kaplan E L, Schwartz R H. Diagnosis and management of group A streptococcal pharyngitis: a practice guideline. Infectious Diseases Society of America. Clin Infect Dis 1997; 25: 574-83.

2.- Fica A. Faringoamigdalitis estreptocóccica en adultos y adolescentes. Rev Chil Infect 2002; 19: 79-91.

3.- Denny F W, Wannamaker L W, Brinck W R, Rammelkamp C H Jr. Custer EA. Prevention of rheumatic fever. Treatment of the preceding streptococcal infection. JAMA 1950; 143: 151-3.

4.- Dajani A, Taubert K, Ferrieri P, Peter G, Shulman S. Treatment of acute streptococcal pharyngitis and prevention of rheumatic fever. Pediatrics 1995; 96: 758-64.

5.- Wannamaker L W, Rammelkamp C H Jr, Denny F W, Brink W R, Houser H B, Hahn E O. Prophylaxis of acute rheumatic fever by treatment of the preceding streptococcal infection with various amounts of depot penicillin. Am J Med 1951; 10: 673-95.

6. Middleton D B, D'Amico F, Merenstein J H. Standardized symptomatic treatment versus penicillin as initial therapy for streptococcal pharyngitis. J Pediatr 1988; 113: 1089-94.

7.- Petersen K, Phillips R S, Soukup J, Komaroff A L, Aronson M. The effect of erythromycin on resolution of symptoms among adults with pharyngitis not caused by group A Streptococcus. J Gen Intern Med 1997; 12: $95-101$.

8.- Dagnelie C F, van der Graaf Y, De Melker R A. Do patients with sore throat benefit from penicillin? A randomized double-blind placebo-controlled clinical trial with penicillin $\mathrm{V}$ in general practice. $\mathrm{Br} \mathrm{J}$ Gen Pract 1996; 46: 589-93.

9.- Peyramond D, Portier H, Geslin P, Cohen R. 6-day amoxicillin versus 10-day penicillin $\mathrm{V}$ for group $\mathrm{A}$ beta-haemolytic streptococcal acute tonsillitis in adults: a French multicentre, open-label, randomized study. The French Study Group Clamorange. Scand J Infect Dis 1996; 28: 497-501.

10.- Ioannidis J P A, Contopoulus-Ioannidis D G, Chew P, Lau J. Meta-analysis of randomized controlled trials on the comparative efficacy and safety of azithromycin against other antibiotics for upper respiratory tract infections. J Antimicrob Chemother 2001; 48: 677-89.

11.- Zhanel G G, Walters M, Noreddin A, Vercaigne L M, Wierzbowski A, Embil J M et al. The ketolides: a critical review. Drugs 2002; 62: 1771-804.

12.- Langtry H D, Balfour J A. Azithromycin. A review of its use in paediatric infectious diseases. Drugs 1998; 56: 273-97.

13.- Dunn C J, Barradell L B. Azithromycin. A review of its pharmacological properties and use as 3-day therapy in respiratory tract infections. Drugs 1996; 51: 483505.

14.- Contreras L, Fica A, Figueroa O, Enríquez N, Urrutia P, Herrera P. Resistencia de Streptococcus pneumoniae a penicilina y su asociación con factores clínicos y epidemiológicos. Rev Méd Chile 2002; 130: 26-34.

15.- Deeks S L, Palacio R, Ruvinsky R, Kertesz D A, Hortal M, Rossi A et al. Risk factors and course of illness among children with invasive penicillin-resistant Streptococcus pneumoniae. Pediatrics 1999; 103: 40913.

16.- Fica A, Díaz J C. Enfoque diagnóstico y terapéutico de los pacientes adultos con sospecha de sinusitis aguda. Rev Chil Infect 2003; 20: 184-92.

17.- De Ferranti S D, Ioannidis J P A, Lau J, Anninger W V, Barza M. Are amoxycillin and folate inhibitors as effective as other antibiotics for acute sinusitis? A meta-analysis. Br Med J 1998; 317: 632-37.

18.- Benninger M S, Sedory Holzer S E, Lau J. Diagnosis and treatment of uncomplicated acute bacterial rhinosinusitis: summary of the Agency for Health Care Policy and Research Evidence Based-Report. Otolaryngol Head Neck Surg 2000; 122: 1-7.

19.- Peters D H, Friedel H A, McTavish D. Azitromycin. A review of its antimicrobial activity, pharmacokinetic properties and clinical efficacy. Drugs 1992; 44: 75099.

20.- Contopoulos-Ioannidis D G, Ioannidis J P A, Chew P, Lau J. Meta-analysis of randomized controlled trials on the comparative efficacy and safety of azithromycin against other antibiotics for lower respiratory tract infections. Antimicrob Agents Chemother 2001; 48: 691-703.

21.- Schonwald S, Barsic B, Klinar I, Gunjaca M. Threeday azithromycin compared with ten-day roxithromycin treatment of atypical pneumonia. Scand J Infect Dis 1994; 26: 706-10.

22.- Bartlett J G, Dowell S F, Mandell L A, File T M Jr, Musher D M, Fine M J. Practice guidelines for the management of community-acquired pneumonia in adults. Clin Infect Dis 2000; 31: 347-82.

23.- Mandell L A, Marie T J, Grossman R F, Chow A W, Hyland $\mathrm{R} \mathrm{H}$, and the Canadian community-acquired pneumonia working group. Clin Infect Dis 2000; 31: 383-421. 
24.- González P, Acuña G, Ballesteros J, Cabello H, Castillo C, Chernilo S, et al. Tratamiento de la neumonía. Rev Chil Enf Respir 1999; 15: 91-7.

25.- Kuo C C, Jackson L A, Campbell L A, Grayston J T. Chlamydia pneumoniae (TWAR). Clin Microbiol Rev 1995; 8: 451-61

26.- Mandell L A, Bartlett J G, Dowell S F, File T M, Musher D M, Whitney C. Update of practice guidelines for the management of community-acquired pneumoniae in immunocompetent adults. Clin Infect Dis 2003; 37: 1405-33.

27.- Fica A. Enfoque terapéutico de la neumonía adquirida en la comunidad. Rev Chile Infect 2002; 19: 207-19.

28.- American Thoracic Society, Standards for the diagnosis and care of patients with chronic obstructive pulmonary disease. Am J Respir Crit Care Med 1995; 152: S77-S120.

29.- Niederman M S. Antibiotic therapy of exacerbations of chronic bronchitis. Semin Respir Infect 2000; 15:59-70.

30.- Wasilewski M M, Johns D, Sides G D. Five-day dirithromycin therapy is as effective as seven-day erythromycin therapy for acute exacerbations of chronic bronchitis. J Antimicrob Chemother 1999; 43: 541-8.

31.- Barman-Balfour J A, Figgitt D P. Telithromycin. Drugs 2001; 61: 815-29.

32.- Allegra L, Blasi F, de Bernardi B, Cosentini R, Tarsi P. Antibiotic treatment and baseline severity of disease in acute exacerbations of chronic bronchitis: A reevaluation of previously published data of a placebocontrolled randomized study. Pulm Pharmacol Ther 2001; 14: 149-55.
33.- Warren J W, Abrutyn E, Hebel R, Johnson J R, Scaheffer A J, Stamm W E. Guidelines for antimicrobial treatment of uncomplicated acute bacterial cystitis and acute pyelonephritis in women. Clin Infect Dis 1999; 29: 745-58.

34.- Fica A. Manejo ambulatorio del síndrome diarreico agudo en adultos. Rev Chil Infect 2001; 18: 108-26.

35.- Bhattacharya S K, Bhattacharya M K, Dutta P, et al. Randomized clinical trial of norfloxacin for Shigellosis. Am J Trop Med Hyg 1991; 45: 683-7.

36.- Bennish M L, Salam M A, Khan W A, Khan A M. Treatment of Shigellosis: III. Comparison of one- or two-dose ciprofloxacin with standard 5-day therapy. A randomized, blinded trial. Ann Intern Med 1992; 117: $727-34$

37.- Gotuzzo E, Oberhelman R A, Maguina C, Berry S J, Yi A, Guzmán M, et al. Comparison of single-dose treatment with norfloxacin and standard 5-day treatment with trimethoprim-sulfamethoxazole for acute shigellosis in adults. Antimicrob Agents Chemother 1989; 33: 1104-4.

38.- Khan W A, Seas C, Dhar U, Salam M A, Bennish M L. Treatment of Shigellosis: V. Comparison of azithromycin and ciprofloxacin. A double-blind, randomized, controlled trial. Ann Intern Med 1997; 126: 697703.

39.- Center for Disease Control and Prevention. Sexually Transmitted Diseases. Treatment guidelines 2002. Morb Mortal Wkly Rep MMWR 2002; 51(RR-6).

40.- Lau C Y, Qureshi A. Azithromycin versus doxycycline for genital Chlamydial infections. STD 2002; 29: $497-$ 502 .

Correspondencia a:

Alberto Fica Cubillos

E-mail: afica@ns.hospital.uchile.cl 